\title{
EL MUNDO CLÁSICO EN AGUSTÍN MILLARES TORRES: LA «INTRODUCCIÓN» A SU HISTORIA GENERAL DE LAS ISLAS CANARIAS
}

\author{
Francisco Salas Salgado \\ Universidad de La Laguna \\ frasalas@ull.edu.es
}

\begin{abstract}
RESUMEN
El Mundo Clásico no ha pasado desapercibido para la historiografía canaria. Muchos historiadores de diversas épocas han atendido el aspecto mítico de estas Islas con referencia a sus fuentes, realizando de paso interpretaciones diversas sobre aquellas. El siglo XIX conoció un buen número de personalidades con inquietudes diversas que emprendieron esta labor con mejor o peor fortuna. Entre estos destaca la figura de Agustín Millares Torres que junto con Gregorio Chil y Naranjo se consideran prototipos de la historia liberal burguesa. Atendiendo a lo anterior, se pretende en este trabajo destacar y analizar las referencias que existen al respecto en la "Introducción» de su Historia general de las Islas Canarias.
\end{abstract}

Palabras ClaVe: Pervivencia clásica; Mitología; Islas Canarias; Siglo XIX.

THE CLASSICAL WORLD IN AGUSTÍN MILLARES TORRES:

THE «INTRODUCTION» TO HIS HISTORIA GENERAL DE LAS ISLAS CANARIAS

\section{ABSTRACT}

The Classical World has not gone unnoticed to Canarian historiography. Throughout the different periods, historians have shown their concern about the mythical past associated to these islands, rendering their own interpretations of such stories with unequal success. In the nineteenth century a considerable number of Canarian scholars joined that intellectual tradition. Among these, Agustín Millares Torres and Gregorio Chil y Naranjo are acknowledged as representing prototypical liberal bourgeois historiography. Taking this into account, this work aims to highlight and analyse the references to the Classical world in Millares Torres' «Introduction" to Historia general de las Islas Canarias.

KeYwORDs: Classical Survival; Mythology; Canary Islands; 19th Century.

Hace años el profesor Marcos Martínez comenzó una línea de investigación interesante e importante sobre pervivencia clásica, relacionada con la imagen de Canarias en la Antigüedad. Si no recuerdo mal, a él se debió la idea inicial de crear una revista relacionada con la Filología y la Cultura Clásicas, que debía vincularse 
al departamento de Filología Clásica de la Universidad de La Laguna, cuyo nombre final, Fortunatae, fue propuesto por el profesor Fremiot Hernández González.

Con ocasión del treinta aniversario de esta revista y animado por la invitación, enviada por el equipo de dirección actual, a participar en este homenaje a todos los que colaboramos en aquel ya lejano primer número, me ha parecido conveniente realizar un trabajo que continuara la línea de investigación antes indicada, relacionado además con el título que se nos proponía. En este caso el tema elegido tiene que ver con la presencia del mundo clásico en la historiografía canaria ${ }^{1}$, eligiendo para ello la obra de uno de los historiadores más conocidos del siglo XIX, el grancanario Agustín Millares Torres. Curiosamente una de las investigaciones que se ocupan de la literatura en Canarias en esa centuria, debida a María Rosa Alonso², se encuentra en la reedición hecha con posterioridad de la obra de este autor donde vamos a estudiar esta presencia clásica, la Historia general de las Islas Canarias ${ }^{3}$.

Había incluido M. Martínez (cf. 2007: 309) a este polígrafo grancanario en la nómina de los historiadores del siglo $\mathrm{XIX}^{4}$ cuya obra tiene alguna relevancia para la tradición clásica, algo que viene a incidir en la dimensión humanista que también se ha querido ver en su obra (cf. Torre Champsaur, 1966).

Su biografía es suficientemente conocida. Parte sobre todo de los datos que ha dejado escritos el propio historiador en unas memorias (cf. Millares Torres, 1940), junto a los que se ofrecen en otros estudios, algunos debidos a miembros de su familia (cf. Bosch Millares, 1959; Luxán Meléndez, 1996; y Jorge Millares, 2005).

En efecto, nació este historiador, poeta, novelista, publicista, músico y notario en Las Palmas de Gran Canaria en el año 1826. Sus primeros estudios los comenzó con el maestro Pedro Alfonso en el año 1833, ya sabiendo leer, ingresando en 1839 en el Seminario Conciliar como alumno externo para cursar el bachillerato. Aquí estudió, el primer año, Rudimentos de Latín; y el segundo y tercero, composición y traducción de clásicos, además de elementos de Retórica y Poética con el racionero Enrique Hernández Rosado; el cuarto año, Matemáticas y Lógica; el quinto,

${ }^{1}$ M. Martínez (1996: 253-255) explicaba aquí el diferente tratamiento que se ha hecho en la historiografía canaria de todas las épocas del mundo clásico, especialmente de su pasado mítico. Aunque la mayor parte de estas obras siempre daban cabida a capítulos relacionados con esta temática, la rigurosidad en sus análisis y las variadas conclusiones a que se llegaba no eran siempre afortunadas.

${ }^{2}$ M. ${ }^{a}$ R. Alonso (1977: 115) calificaba a nuestro historiador como adalid del Romanticismo en su isla y destacaba su incansable laboriosidad.

${ }^{3}$ Hago notar que, en la transcripción de los textos de esta obra, como también de otras fuentes antiguas citadas, se respeta la ortografía y la puntuación originales.

${ }^{4}$ Nombra, además (cf. Martínez, 2007: 309), a Gregorio Chil y Naranjo, José García Ramos, Rosendo García Ramos y Bretillard, Waldo Giménez Romera, Carlos Pizarroso y Belmonte, Antonio María Manrique y Saavedra, José Agustín Álvarez Rixo, Cipriano de Arribas y Sánchez, P. J. de las Casas Pestana, Manuel de Ossuna y Saviñón y Domingo Déniz Grek. A esta nómina añadía algunos autores extranjeros de ese siglo que impulsaron los estudios históricos de las Islas, caso de R. Verneau, Sabin Berthelot, Philip Barker-Webb, Leopold de Buch, Bory de Saint-Vincent y J. Bute. 
el segundo curso de Matemáticas y Física, y el sexto año, Historia de España, Metafísica y Literatura. Al concluir el segundo año de Latinidad se recitaban en un día determinados pasajes en esta lengua con la finalidad de conseguir buenos oradores. Compatibilizaba, además, estas enseñanzas con clases de solfeo y violín que recibía de su padre, y con las de dibujo que realizaba en la Academia regentada por Silvestre Bello, situada en el edificio del Ayuntamiento.

Terminados los estudios secundarios en 1844, su padre creyó conveniente que fuera a estudiar leyes a la Universidad de La Laguna. Sin embargo, el cierre de esta institución hizo que su progenitor le matriculara en la Escuela de Notariado que acababa de abrir en Las Palmas de Gran Canaria, lo que compaginó con la composición literaria y musical y con la lectura constante de obras diversas, entre ellas, particularmente, la Historia de Canarias de Viera y Clavijo que «despertó el deseo de escribir otra más extensa y mejor combinada» (Bosch Millares, 1959: 25).

Viajó posteriormente a Madrid para afianzar sus estudios musicales, regresando en 1849 de nuevo a la isla tras conocer el fallecimiento de su padre, momento en que empieza a ayudar a la economía familiar con la impartición de clases de solfeo en el Colegio de San Agustín. Se casa dos años más tarde con Encarnación Cubas Báez, fruto de cuyo matrimonio nacieron once hijos, fundando una estirpe de intelectuales reconocidos en la sociedad grancanaria.

Ejerció luego la dirección de los periódicos «El Ómnibus» y «El Canario», en los que también escribía, momento en que empieza a retomar su interés por la historia. Así escribiría en 1860 una Historia de la Gran Canaria, primero para colmar su afición a esta clase de estudios y segundo para defenderla "de los apasionados ataques de su rival Tenerife» (Millares Torres, 1840: 36), donde narra los sucesos notables ocurridos en la isla hasta la segunda división administrativa de la provincia. Continuó esta labor con la publicación de la Historia general de las Islas Canarias, cuya primera edición se imprimió en el año 1882 y, la segunda, en 1893, extensa monografía que la Real Academia de la Historia premió al nombrarle socio correspondiente de esta isla en dicha institución y a cuya publicación dedicó los últimos años de su vida. Debemos también a esta faceta de historiador su Biografía de Canarios Célebres, aparecida en 1871, y la Historia de la Inquisición en Canarias, fechada el año 1874. Falleció en 1896 a la edad de setenta años tras realizar una ingente e importante labor cultural.

Como se dijo antes, la obra que se va a estudiar aquí es la Historia General de las Islas Canarias. Consta la misma de diez tomos publicados en Las Palmas de Gran Canaria (Imprenta de la Verdad de Isidro Miranda) en los años 1893 (tomos I-IV), 1894 (tomos V-VIII) y 1895 (tomos IX y X).

Es en el primer tomo en el que se van a encontrar noticias relacionadas con el mundo clásico. Se divide en varios apartados. Una dedicatoria «Al lector», la «Introducción», el "Libro primero» donde en doce apartados se hace una descripción geográfica de las Islas, incluida San Borondón, y el «Libro segundo» titulado «Edad Antigua», dividido en seis apartados que tratan de manera más precisa sobre el pasado de las Islas. Estos seis apartados son: I. Filósofos y poetas; II. Egipcios, Persas, Etruscos; III. Fenicia, Cartago, Marsella; IV. Sertorio; V. Juba y VI. Historiadores y Geógrafos. 
Vamos a centrarnos aquí, por motivo de espacio y coherencia temática, solo en la «Introducción» donde existe un análisis más personal y crítico del autor. Dejo la información que se ofrece en el «Libro segundo" para posteriores investigaciones que tratarían de determinar la dependencia de Millares con otras fuentes, en concreto, con la obra de Cristóbal Perez del Cristo y la de Viera y Clavijo5, la cual, como se dijo antes, conocía perfectamente.

Son los apartados segundo y tercero de la «Introducción» los que ofrecen datos relativos al pasado clásico.

El primero de ellos analiza de forma resumida la historia de las Islas Canarias. Se trata de una relación diacrónica, y no siempre ordenada, en la que introduce algunas reflexiones personales, desde las primeras noticias que se tienen de ellas hasta el momento actual. Refiere que la existencia de estas Islas, nunca desconocida para la vieja Europa, aparece en medio de los recuerdos y las referencias, primeros, vagos y envueltos en oscuras leyendas, que las vinculan con determinados pueblos, entre los que menciona al pueblo egipcio ${ }^{6}$, existencia además pregonada por los poetas de aquellas edades remotas.

Considera cierto que estas Islas fueron descubiertas luego por los pueblos comerciales del litoral mediterráneo, que las visitaron y colonizaron, y este recuerdo se perdería en el correr de los tiempos «ahogado á intérvalos bajo las sucesivas oleadas de los pueblos invasores» (Millares Torres, 1893: 4).

El Renacimiento pondría fin a la ignorancia que existió en los siglos medios, los cuales propiciaron la difusión del adjetivo de «afortunadas» con que se las conocía desde antiguo por determinadas circunstancias, especialmente su situación:

${ }^{5}$ Todos los temas que trata Millares en el «Libro segundo» aparecen en los tres primeros libros de las Noticias de la Historia General de las Islas Canarias de Viera y Clavijo. Sin embargo, se ha sugerido (cf. Martínez, 1996: 23-24) que, a este respecto, existe más vinculación con la obra de Cristóbal Pérez del Cristo. Entre estos historiadores decimonónicos, aparte de Millares Torres, estarían Gregorio Chil y Naranjo, José García Ramos y Rosendo García Ramos y Bretillard. Convendría también ampliar el rastreo a otras obras anteriores, ya canónicas en la historiografía canaria, como son la de fray Alonso de Espinosa y la de fray Juan de Abreu Galindo.

${ }^{6}$ Se refiere expresamente a «las oscuras leyendas de los sacerdotes egipcios» (Millares Torres, 1893: 4), algo que tiene que ver con el mito de la Atlántida. Esta referencia tiene gran relación con lo que comenta Viera y Clavijo al cuestionarse si fueron las Canarias parte de la Atlántida de Platón. Dice así: «¿Adquiriría este mar la denominación de Atlántico por haber reemplazado el sitio que ocupaba antes de su ruina la famosa Atlántida de Platón? O, lo que es lo mismo, ¿̇se llamarían Atlánticas estas islas por ser como los fragmentos, reliquias y porciones más elevadas de aquella infeliz tierra? Yo no me atrevería a hacer estas preguntas, si el diálogo Critias o el Timeo del mismo Platón estuviese absolutamente convencido de fabuloso, y si no hallase hombres de sana crítica, inclinados a darle asenso y a discurrir acerca de él con toda seriedad. Este filósofo, pues, que fue un autor de admirables prendas, y que por su carácter sincero, penetrativo y grave está reputado generalmente por amante de la verdad, y aun se le dio el renombre de Divino, introduce en el citado diálogo las noticias que en orden a la Atlántida había adquirido Solón por el conducto de los sacerdotes de Egipto, quienes conservaban las memorias de su existencia y destrucción» (Viera y Clavijo, 1982: I, 37-38). 
Ya fuese por su situación excepcional en las fronteras del mundo conocido, más allá de esas misteriosas columnas, terror de los más osados navegantes; yá por la creencia, cada vez más arraigada en la conciencia universal, de que la mansión prometida á los justos se encontraba en esas codiciadas Islas, dónde, bajo una primavera eterna, se alzaba oculto y maravilloso el paraiso terrenal, el archipiélago recibió el nombre de Afortunado, multiplicándose de siglo en siglo tan poéticas fábulas, y siendo decorado su suelo con todas las bellezas que la fantasía era capaz de inventar, yá le prestase el Paganismo su mágica paleta, yá el Cristianismo lo envolviese en su místico ropaje (Millares Torres, 1893: 4-5)7.

Esta etapa, que sucede a la época que mira a las Islas desde la fábula, alusión a la Antigüedad grecolatina, y que es «cuna de la edad presente» (Millares Torres, 1893: 5) ${ }^{8}$, favorece que las Islas vuelvan a surgir alejadas de lo mítico. En ese momento comienza a ser visitada por aventureros de todas las naciones, "piratas ennoblecidos» que recorren pueblos para saquearlos y recoger prisioneros.

Algunos de los nobles aventureros que menciona Millares Torres y sus gestas son sumamente conocidos en el marco de la historia de las Islas: los primeros Juan de Bethencourt y Gadifer de la Salle, en el deseo de convertir infieles, bajo la protección de Juan II de Castilla, someten Lanzarote, Fuerteventura y El Hierro, «viniendo solo a quebrantar sus fuerzas en las playas de la Gran-Canaria, de donde es vigorosamente rechazado, tantas cuantas veces intenta pisar su libre suelo» (Millares Torres, 1893: 7). Tras la marcha de Bethencourt, "el reino de Canarias» pasa de mano en mano hasta que el noble sevillano, Diego García de Herrera, casado con Inés Peraza, lo adquiere trasladándose a sus dominios para someter las Islas que no habían sido conquistadas. La dificultad de esta empresa hace que acepte la proposición que le brinda la «Católica Isabel» y ceda en 1478 a la Corona de Castilla el dominio de aquellas tres islas, cuya importancia era bien conocida de los sabios consejeros de esa Reina. Gracias a esto se pudo someter al resto de islas, proceso en el que la religión cristiana tuvo gran protagonismo. El «orgullo castellano y el desprecio que pueblos infieles é idólatras» causaron en estos fieros conquistadores hicieron que se borrara inmediatamente todo vestigio de las leyes, usos, costumbres y lenguaje de los aborígenes.

${ }^{7}$ Autores paganos y cristianos aparecen en la extensa lista que hace Pérez del Cristo (1996: 9-13) sobre las fuentes que nombran estas islas «yà con el nombre moderno de Canarias; yà con los antiguos de Islas Afórtunadas, Atlanticas, y Campos Elisios».

${ }^{8}$ En efecto, a partir del siglo XIV, la Europa del primer Renacimiento vuelve a descubrir el Archipiélago con motivo de una reciente singladura atlántica que buscaba nuevas rutas en la búsqueda del oro africano. Millares (1893: 5) califica este momento como época de transformación, donde una savia nueva viene a dar impulso a las ciencias, artes y letras, donde el pensamiento está dispuesto a lanzarse por sendas inexploradas, sacude el polvo del pasado y se lanza sin temor al porvenir. Quizás detrás de esta expansión, como sugiere M. Martínez (cf. 1992: 15-16), estuvieron algunos mitos clásicos que impulsaron esas expediciones colonizadoras. 
Apunta algo sobre los siglos anteriores a esta época, que denomina prehistóricos, complicados de estudiar y sobre los que solo el estudio comparado del lenguaje, junto con el análisis de los cráneos, permitirá en el futuro ofrecer datos, dado lo avanzado de las ciencias antropológicas.

Terminada la conquista, la historia siguiente del Archipiélago no ofrece para este historiador interés alguno, pues repite los esquemas heredado de la Península ibérica

en la esfera gubernamental, el poder absoluto de derecho divino, pesando sobre el organismo social, y deteniendo su desenvolvimiento. En la esfera de las ideas, el poder absorvente de la inquisición, ahogando toda manifestación heterodoxa y paralizando el vuelo de la ciencia libre (Millares Torres, 1893: 10).

Termina comentando que, debido a esto, una nación, que por su posición estratégica y geográfica estaba llamada a ser grande y poderosa, quedó sumida en un grado de ignorancia y sumisión, como otras provincias y colonias españolas, aunque en algunos momentos esta misma situación provocara cierta rebelión ante la opresión inquisitorial y los jefes militares.

Como se puede observar, en esta particular reseña histórica del Archipiélago solo existe, en relación con el mundo clásico, aquella exigua referencia, que tiene que ver con la denominación de afortunadas que se dio a las Islas.

Es en el siguiente apartado donde se ofrecen más datos del pasado mítico insular con mención a las fuentes (poetas, filósofos, geógrafos e historiadores) que en la Antigüedad y comienzos de la Edad Media habían escrito sobre ello.

Empieza así, al comienzo, a plantear algunas cuestiones problemáticas, en concreto, las que tienen que ver con las fuentes clásicas que tratan del Archipiélago. Critica el desigual tratamiento que realizan (algunas "formal», otras «incidentalmente») y la dependencia de unas y otras que se copian con frecuencia. A ello añade la mezcla que a menudo existe entre las escasas y contradictorias noticias que ofrecían mercaderes y navegantes que visitaban las islas con «las mil y mil fábulas, que al transmitirse verbalmente aquellas narraciones, se inventaban por la ignorancia y la vanidad, ó por esa inclinación á lo maravilloso, que es propio de nuestra naturaleza» (Millares Torres, 1893: 12).

Empero, de este conjunto de fábulas relacionadas con el pasado de las Islas, hay algunas que parecen ser más evidentes que otras, en concreto, que en esta tierra pudiera existir el Jardín de las Hespérides (también el Paraíso de Adán y la Mansión de los Justos), mito que, al considerar las Islas como una tierra excepcional, ha inflamado la imaginación de los poetas y el relato absurdo de los historiadores, y que se reproduce en las diversas crónicas escritas «sin que de ellas aparezcan noticia alguna, que pueda desafiar impunemente la moderna crítica» (Millares Torres, 1893: 12).

Plantea, en este punto, diversas cuestiones que no desarrolla de forma ordenada, mezclando relatos fabulosos con textos que tratan del pasado mítico.

En efecto, tras la dificultad que observa en el mito de la Atlántida, tema de difícil solución para los que quieran estudiarlo, menciona las obras de Platón

${ }^{9}$ La crítica moderna (cf. Martínez 1992: 131-132) insiste en esta dificultad, en las diferentes posturas que han existido en relación a este mito, distinguiendo, primero, los que creen en la historicidad 
como primera fuente escrita en la que se hace referencia del Archipiélago. El resto de las fuentes griegas es conocido, así como la onomástica que en ellas se ofrece, aunque ninguna de ellas ha logrado aportar datos convincentes:

Despues de los diálogos de Solón y Cricias, hallamos tambien un recuerdo de las Afortunadas en Homero, Hesiodo, Pindaro y otros poetas de los siglos heróicos de la Grecia, sin que sus versos hayan conseguido esclarecer ninguna cuestión importante á este Archipiélago, siendo dudoso si, bajo el nombre de Hespérides, Górgonas, Atlánticas, Campos Elíseos, y otros, quisieron aquellos escritores designar las Islas de la costa occidental de Africa, ó los grupos más lejanos de las Azores, Cabo Verde y Antillas (Millares Torres, 1893: 13).

Se queja Millares Torres de la poca fidelidad que ofrece el relato de los historiadores y poetas romanos de la República hasta Augusto, los cuales reprodujeron esas fábulas sin analizar la veracidad de las mismas. Este hecho hace que quienes vayan a usarlas o consultarlas puedan encontrar en ellas poca información sólida.

Sin embargo, a renglón seguido, acepta el relato de Heródoto, que trata la conocida circunnavegación fenicia de África apoyada por el faraón Necao II, en la posibilidad, que considera casi cierta, de que pudieran avistar en su viaje alguna de las islas orientales:

No sucede lo mismo con la relación de Herodoto, cuando al hablarnos de la expedición que el Rey Necos preparó en Egipto, de cuya ejecución encargó á los fenicios, declara que, saliendo los buques del golfo arábigo, regresaron por las columnas de Hércules, despues de tres años de navegación; añadiendo luego, que un sobrino de Darío emprendió tambien otro viaje allende el estrecho, y habiendo seguido las costas meridionales del Africa, doblado el cabo Soloeis, había visto hombres vestidos con hojas de palma, que huyeron al descubrirle, refugiándose en sus montañas. No es aventurado suponer, que ambas expediciones encontraran á su paso el grupo oriental de las Canarias, y descansaran en sus accesibles playas, porque, no separándose los pilotos del litoral, debieron necesariamente descubrir á Lanzarote y Fuerteventura, y tal vez la Gran-Canaria (Millares Torres, 1893: 14) ${ }^{10}$.

Igual consideración muestra de las obras de Eutimene y Piteas de Marsella, que hubieran podido, de haberse salvado íntegras, esclarecer algunas cuestiones

(quizás deformada) del relato; segundo, los que creen que existió en algún lugar y, por tanto, habría que buscarla; tercero, los que consideran que se trata de una compilación de leyendas y hechos históricos de diversos pueblos y épocas; cuarto, los que piensan que solo es ficción que sustenta una utopía político-social y, finalmente, los que creen que la idea de la Atlántida presupone el conocimiento de América.

${ }^{10}$ La teoría que sugiere este historiador, sobre la posibilidad de avistamiento de las Islas, es aceptada en algunas investigaciones recientes (cf. Santana Santana - Arcos Pereira, 2002), que consideran que los fenicios conocerían la ruta para evitar las calmas y corrientes antiguas en su circunnavegación por África. Esta ruta se adentra en el Océano Atlántico muchas millas para luego regresar hasta las costas africanas por las islas de Cabo Verde y Canarias. 
sobre el Archipiélago, aceptando la idea de que al salir del estrecho seguramente pudieron avistar tierras africanas y algunas de las islas Canarias.

Da cuenta, de igual forma, de otras expediciones realizadas por diferentes pueblos, algunas de las cuales también pudieron arribar a las Islas.

Las primeras podrían haber sido realizadas por los etruscos, hipótesis que -comenta- algunos historiadores apuntan. Este pueblo poseía una flota naval que le permitió dominar el Mediterráneo durante algunos siglos y tiene por cierto que llevaron sus naves al Atlántico deseando expandir su comercio y poder marítimo y pudiendo colonizar los sitios más favorables que junto al Estrecho fueron encontrando.

Las «Repúblicas de Tiro y Cartago» comandaron nuevas expediciones, derivadas sobre todo de su condición comercial, entre las que destaca la realizada por Hannón, que ha suscitado interpretaciones diversas entre los comentadores.

Lo mismo ocurre con otra de las expediciones que más se conocen, la que realizara Sertorio, de la cual refiere:

Cuando Sertorio, dueño de la Iberia, paseaba sus triunfantes legiones hasta las costas de la Lusitania, seducido por la descripción que unos navegantes le hicieron de las Afortunadas, se dice, intentó trasladarse á ellas, según nos refiere Plutarco, lo cual, aunque parece no llegó á tener efecto, dió ocasión á este escritor para consignar tan interesante noticia, que es por si sola una prueba evidente del conocimiento que los marinos conservaban de la existencia de aquellas Islas, y de la facilidad con que se navegaba entonces por el Atlántico (Millares Torres, 1893: 16).

No se olvida, en fin, de mencionar a Juba II, «sobre cuyo viaje escribió un libro, que desgraciadamente se ha perdido, pero del cual nos conserva Plinio algunos preciosos fragmentos en su tratado de Historia Natural» (cf. Millares Torres, 1893: 16-17), de cuya huella -también de otras expediciones anteriores, egipcias y líbico púnicas- son las inscripciones grabadas en basalto o rocas volcánicas que se han encontrado en alguna de las islas, en concreto en El Hierro, La Palma y Gran Canaria, en su momento misteriosas y que probablemente la ciencia del porvenir podrá interpretar.

Nada más hay en esta «Introducción» relacionado con el pasado antiguo de Canarias, solo la mención de un puñado de autores que tratan los primeros siglos de la Edad Media donde los recuerdos del Archipiélago estaban en tinieblas, aceptando la posibilidad de la llegada de misioneros, vándalos u otras hordas del norte que empujados por feroces tribus pudieran pasar desde Europa al África y luego haber llegado aquí.

Habría que destacar, también, el correcto tratamiento que hace de las fuentes clásicas (cf. Cabrera Perera, 1988: 85-97) que señala. Es sensato pensar que al tratarse de un resumen no exista una relación exhaustiva. Por lo demás son los autores griegos los que más aparecen frente a los latinos, quizás, como antes se dijo, por la escasa crítica que estos hicieron de los textos griegos, limitándose solo a transmitir los datos como meros copistas.

En efecto, el primer autor que cita en el texto es Platón. Refiere en concreto: «diálogos de Solón y Cricias» en relación al mito de la Atlántida. 
Cuando habla del mito de las Afortunadas alude a Homero, Hesíodo, Píndaro y «a otros poetas de los siglos heroicos de Grecia», referencia que amplía en nota así:

Iliada. L. 18, v. 606. L. 20, v. 7; Odisea L. 4. v. 563 á 568; Hesiodo. Opera et Dies. v. 171. Pindaro. Olymp. 2, Ant. 4. v. 77 y 78 (Millares Torres, 1893: 13) ${ }^{11}$.

Las otras fuentes tienen que ver con los diferentes viajes y exploraciones que se hicieron en la Antigüedad. Nombra así a Heródoto («Herodoto. Lib. 4, cap. 42») en relación a la expedición marítima para circunnavegar África, auspiciada por el rey egipcio Necao (habría que añadir, por lo que apunta Millares, también el capítulo siguiente de dicho libro, donde se habla del sobrino de Darío).

Hace también mención a las obras perdidas de Eutimene y Piteas de Marsella. De este último en nota expone:

Pytheas escribió dos obras: La vuelta al mundo, y el Océano, que desgraciadamente se han perdido, no quedando de ellas sino fragmento en Strabon y Plinio. Véase, Pytheas de Marseille et la Geographie de son temps, par Lelewel, París, 1836 (Millares Torres, 1893: 15).

Entre los comentadores del periplo de Hannon, cita en nota a Plinio («Plinio. Lib. 2, cap. 67»), a Polibio y a Festo Avieno («Ora marítima, v. 117 y $412 »)$, a los que añade los siguientes autores y obras modernos, con algún comentario:

Bochart. Geographia sacra I, 13.

Campomanes. Antigüedad maritima de Cartago.

Dodwell. Dissertatio prima in geograph. min.

Bougainville. Memoires sur les decouvertes d'Hannon, dans les memoires des Inscrip. t. 26 y 28.

Gosselin. Recherches sur la geo. des anciens T. 1. ${ }^{\circ}$, p. 63.

Rennel. Geo. of Herodotus, p. 910.

Heeren. De la Politique et du Commerce des Peuples de l'antiquité. T. 4º, p. 101, 196 y 318. En un apéndice al mismo tomo se halla el texto íntegro (Millares Torres, 1893: 15).

${ }^{11}$ Debe entenderse la inclusión de la Ilíada como fuente por la mención que se hace del Océano en los dos pasajes que se citan de esta obra de Homero. Se trata de un tema que tiene gran importancia para la ubicación en Canarias de los mitos greco-latinos. Al respecto M. Martínez (1992: 34), entre otras cosas, comenta: «[...] lo que importa resaltar aquí en relación con nuestro tema es el hecho de situar en el Océano todo lo que en el mundo era extraño y fabuloso: los etíopes, los cimerios, los pigmeos, Gerión, las Gorgonas, las Hespérides, etc. El Océano era el lugar de alejamiento por excelencia, hasta el punto de que ya desde Homero se practicaba el exōkeanismós, la oceanización, es decir, la tendencia a trasladar a los bordes del Océano pueblos y lugares que de ordinario se situaban en otra parte, como cuando la nave Argo navega a Grecia de oeste a este, o cuando se sitúan los cimerios en las riberas del Océano, siendo así que la mayoría de los historiadores los colocaban entre los escitas. La práctica de la oceanización tiene como corolario instalar en los contornos del Océano los países y lugares utópicos, imaginarios o escatológicos, en el sentido teológico del término». 
Plutarco es la fuente del relato de Sertorio (refiere una edición moderna) y señala a Plinio («Plinio. Hist. nat. L. 6. ${ }^{\circ}$, cap. 37») con relación a la expedición de Juba, rey de Mauritania.

Para finalizar refiere algunas fuentes que aluden a Canarias en los primeros siglos de la Edad Media y algunas de sus aportaciones:

Los autores que en este oscuro periodo hablan de las Canarias son:

Pomponio Mela en su Compendio Geográfico. L. 3. ${ }^{\circ}$, cap. 10.

Ptolomeo, que las coloca en un mismo meridiano. L. 4, cap. 6. ${ }^{\circ}$.

Agathemero y Solino, que copian á Plinio, y escriben en el siglo III.

Eumenio, que á fin del mismo siglo dudaba yá de la existencia del Archipiélago.

Dionisio Periegeta y Marciano de Heraclea, á principios del IV, y Rufo Festo Avieno, á mediados del mismo siglo, afirman que el Atlántico es innavegable.

Junior Philosopho, en su Descripcion de todo el orbe, asegura, que allende de las columnas de Hércules, se halla el fin del mundo.

Sulpicio Severo, escritor del siglo v, duda que las Islas sean abordables.

Orosio, Julio Honorio, Marciano Capella y Ethico, reproducen á Plinio con mayor ó menor exactitud.

Prisciano, que escribe en el siglo VI, San Isidoro en el VII, Dicuil y el anónimo de Rávena en el IX, Tzetes en el XII, y Eustaquio en el XIII, copian á Scilax, Dionisio y Avieno (Millares Torres, 1893: 18).

Visto esto, se podría considerar que, dado el carácter de síntesis que tiene esta «Introducción», los datos que se ofrecen sean heterogéneos, pero también subjetivos (este historiador señala lo que considera más relevante), circunstancia que puede explicar las carencias que existen y lo desordenado, a veces, del relato. Debe verse, por tanto, este resumen de las diferentes etapas de la historia de Canarias como ejemplo de análisis personal y crítico. Ello motiva la peculiar forma con que se trata aquí el pasado mítico del Archipiélago y que no aparezcan todos los temas que tienen que ver con ese pasado legendario de las Islas ni se nombren todas las fuentes.

Insiste, primero, Millares en la confusión e imprecisión de las noticias que han ofrecido los escritores de la antigüedad y censura que muchas de estas fuentes repitan esos datos sin depurarlos ni analizarlos.

Se entiende, por ello, que considera la veracidad como la característica que debe buscarse en esos textos antiguos. De resultas de ello, solo nombra (y admite) como ciertos determinados mitos, destacando, sobre todo los relatos, comúnmente aceptados, que tienen que ver con la literatura o fuentes de viajes (seguramente en esto tendría algo que ver las investigaciones que consultara de su época, algunas de las cuales aparecen antes). Aunque no lo diga claramente, parece aceptar el hecho de que, en esas expediciones realizadas por diversos motivos, se llegara a regiones nuevas y que las Islas fueran una de ellas.

Tales consideraciones pueden tener relación con la concepción que de la historia tenía este autor y la intención final que pretendía conseguir con una obra de esta clase.

En efecto, ya en la dedicatoria "Al lector», especie de apología de los estudios históricos como medio para el progreso y adelanto intelectual, reivindica la importancia que en ese momento tenían las islas Canarias y el interés que ofrece desde 
diferentes puntos de vista -especialmente geológico, antropológico y etnográficocon el fin de que el conocimiento del pasado (nada dice del pasado mítico) sirva para ilustración del momento presente y advertencia del porvenir. La necesidad de poseer una historia propia en un libro que sea resumen del «origen, costumbre y lenguaje de la raza que pobló estas Islas, las leyendas de su pasado, sus luchas con las huéstes conquistadoras, su vida actual, y las promesas que su suelo guarda para el porvenir» (Millares Torres, 1893: VIII) es el objetivo al que aspira esta obra, insistiendo en la utilidad de esta clase de trabajos para despertar la afición en las generaciones venideras que con mayor acierto y abundancia de datos vendrán a satisfacer la curiosidad de los que quieren conocer mejor la historia de su país, de unas islas que se hallan cercanas al continente africano que «sitiado por la civilización, no tardará en entregar sus maravillosos secretos á la ciencia» (Millares Torres, 1893: IX).

Asimismo, en el primer capítulo del tomo primero, comenta que, a pesar de ser pequeño el pueblo que habitaba estas tierras cuando «Europa lo ató al carro de su triunfante civilización", no por ello deja de ser interesante

averiguar el origen de aquella raza indómita; recoger los perdidos restos de su lenguaje, religión y costumbres; penetrar en el curioso arcano de su aparición; ofrecer un cuadro exacto de su cultura intelectual, antes que fatalmente se fundiera en la raza vencedora; observar luego sus lentos progresos, hasta llegar á la época actual; seguir paso á paso la ascensión de su nivel sobre la superficie ilustrada del Globo; escudriñar las causas que han paralizado, retrogradado ó impelido ese movimiento; estudiar, en fin, el pasado, presente y porvenir de esas Islas (Millares Torres, 1893: 2).

J. Bosch Millares, nieto de este historiador, también destacó algunas características de esa obra (acopio de documentos, su carácter sintético y la atención preferente a los momentos actuales), recibida en su momento por el público con «natural curiosidad», pero a la que no se criticó por el prestigio y personalidad de su autor en el mundo de las letras:

Esta historia cuya preparación llevaba a cabo desde años antes, trabajando con todo entusiasmo y aprovechando cuantos legajos, documentos y reseña biográfica caía en sus manos, fue escrita para que sirviera de contribución al mejor conocimiento de la historia de España. Esta obra inspirada en las exigencias de la moderna crítica, bajo un plan armónico y un estilo levantado y digno, condensa, en sus páginas, todo lo que hasta esta fecha se llevaba publicado sobre estas islas, no sólo en el limitado campo de su evolución a través de los siglos, sino en el más extenso e interesante de sus adelantos en las ciencias, las artes y las letras, progresos de su comercio, agricultura e industria y marcha de su política, gobierno y administración. Al decidirse Millares Torres a su publicación, pensó siempre que la historia no es la obra de un solo hombre, ni una sola civilización, sino que es el producto de la labor constante de las distintas generaciones que traen al campo de la ciencia, nuevos y valiosos elementos, depurados lentamente por la controversia, la observación y la crítica. Por ello, con esta aportación valiosa, contribuyó, como un investigador más, al adelanto científico, literario e histórico de las islas Afortunadas. Es la historia de Canarias más moderna que se conoce, pues todas las que van apareciendo ampliadas y completadas por el estudio de los eruditos, no llegan a la fecha en que Millares la dio por terminada (Bosch Millares, 1959: 74-75). 
Investigaciones más recientes han calificado igualmente esta obra como ejemplo de historia liberal burguesa realizada en Canarias ${ }^{12}$. Sin embargo, como se puede observar, nada se dice en las anteriores consideraciones acerca de su pasado mítico.

No obstante, no me atrevería por ello a afirmar que Millares pertenezca al grupo de historiadores que consideran que la verdadera protohistoria de Canarias empieza a partir del siglo XIV y que todo lo anterior se reducía a un puñado de leyendas y la repetición y creación de una onomástica imprecisa. La relación de Millares con ese pasado clásico debe entenderse teniendo en cuenta la condición que este historiador exige en toda obra histórica y su concepto de historia como resultado del esfuerzo crítico realizado por las diferentes generaciones.

Es evidente que conoce las fuentes antiguas que han tratado del pasado mítico de las Islas, refiere, además, investigaciones modernas relacionadas con esas fuentes y temas y realiza, posteriormente en esta Historia, en un proceso de selección, una descripción más precisa de lo que considera más acorde con aquellos requisitos que condicionan la obra histórica. Necesario en futuros trabajos sería estudiar la deuda que pueda existir con las fuentes que debió consultar, sean los textos clásicos, otras obras historiográficas o los estudios e investigaciones que refiere, en la exposición más pormenorizada que hace en esta Historia general del pasado mítico de las Islas ${ }^{13}$, así como su aportación personal.

\section{REFERENCIAS BIBLIOGRÁFICAS}

AlOnso, Ma . R. (1977): «La literatura en Canarias durante el siglo XIX», en Historia General de las Islas Canarias de Agustin Millares Torres, t. V, Edirca, Las Palmas de Gran Canarias, pp. 112-131.

Bethencout Massieu. A. (1977): «Desarrollo de las investigaciones históricas canarias tras Millares Torres», en Historia General de las Islas Canarias de Agustín Millares Torres, t. I, Edirca, Las Palmas de Gran Canaria, pp. 53-74.

Bosch Millares, J. (1959): Don Agustín Millares Torres. Su vida y su obra como compositor, novelista e historiador, Ediciones Gabinete Literario, Las Palmas de Gran Canaria.

${ }^{12}$ A. Bethencourt Massieu (cf. 1977: 53-55) trata del concepto de historia que tiene Millares Torres apuntando toda una serie de características: aplicación de los métodos experimentales siguiendo a Renan, recepción del darwinismo e idea del devenir histórico como proceso evolutivo, optimismo colectivo y creencia de un progreso indefinido, persistencia de elementos roussonianos al exaltar al hombre primitivo de las islas que corromperá la colonización hispana y la intolerancia inquisitorial, la opresión del tradicionalismo religioso como elemento esterilizador del pensamiento creador, preocupación por la labor erudita, la finalidad de la historia no solo como comprensión del pasado sino como respuesta al quehacer del hombre individual y colectivo en este mundo, comprensión del avance científico de la historiografía como proceso dialéctico y la percepción de la historia como producto de interrelación entre ciencias afines. T. González Pérez (cf. 2002: 227-230) por su parte añade a esto que Millares Torres se remitió a los estudios de Viera y aportó pocas novedades.

${ }^{13}$ Cf. nota 5 del presente trabajo. 
Cabrera Perera, A. (1988): Las Islas Canarias en el Mundo Clásico, Viceconsejería de Cultura y Deportes del Gobierno de Canarias, Madrid.

GonzÁlez Pérez, T. (2002): «Canarias en la historiografía regional», Hist. educ. 21: 215-240.

Jorge Millares, M. (2005): «Agustín Millares Torres. Un historiador, escritor y compositor excepcional», en La enciclopedia de canarios ilustres, Centro de la Cultura Popular Canaria, La Laguna, pp. 92-99.

LuXÁN MELÉNDEZ, S. DE (1996): «Agustín Millares Torres, historiógrafo de las Islas Canarias: su proyecto de formación de una biblioteca isleña» en J. J. LAFORET HERNÁNDEZ (coord.), Estudios de historiografia regional. Jornadas en Homenaje a Agustin Millares Torres, Real Sociedad Económica de Amigos del País, Las Palmas de Gran Canaria, pp. 19-64.

Martínez, M. (1992): Canarias en la Mitología. Historia mítica del Archipiélago, Centro de la Cultura Popular Canaria, Santa Cruz de Tenerife.

Martínez, M. (1996): Las Islas Canarias de la Antigüedad al Renacimiento. Nuevos aspectos, Centro de la Cultura Popular Canaria, Santa Cruz de Tenerife.

MarTíneZ, M. (2007): «La tradición clásica en la historiografía canaria del siglo XIX: Gregorio Chil y Naranjo", El Museo Canario 62: 307-352.

Millares Torres, A. (1893): Historia general de las Islas Canarias, t. I, Imprenta de La Verdad, Las Palmas de Gran Canaria.

Millares Torres, A. (c. 1950): Notas y recuerdos dedicados a mi esposa e hijos 1826-1896, prólogo de Juan Bosch Millares, s.n., s.l.

Pérez del Cristo, C. (1996): Excelencias y antigüedades de las siete islas de Canaria. Facsímil, Año 1679, Gobierno de Canarias - Cabildo de Tenerife, Ayuntamiento de Icod de los Vinos, Santa Cruz de Tenerife.

Santana Santana, A. - Arcos Pereira, T. (2002): «El conocimiento geográfico del océano en la antigüedad", Eres 10: 9-59.

Torre Champsaur, B. DE la (1966): «Agustín Millares Torres, humanista e historiador», Millares: Revista Trimestral Patrocinada por el Museo Canario 7: 277-290.

Viera y Clavijo, J. DE (1982): Noticias de la historia general de las Islas Canarias, introd. y notas de A. Cioranescu, Goya Ediciones, Santa Cruz de Tenerife, 2 tomos. 
